\title{
Guidelines
}

Cerebrovascular Diseases
Cerebrovasc Dis 2013;35:402-418

DOI: $\underline{10.1159 / 000351753}$
Received: May 6, 2013

Accepted: May 7, 2013

Published online: May 23, 2013

\section{Comparison of the European and Japanese Guidelines for the Management of Ischemic Stroke}

\author{
Rolf Kern ${ }^{a}$ Masao Nagayama ${ }^{b}$ Kazunori Toyoda ${ }^{c}$ Thorsten Steiner ${ }^{d, e}$ \\ Michael G. Hennerici ${ }^{a}$ Yukito Shinohara ${ }^{f}$ \\ ${ }^{a}$ Department of Neurology, UMM, University of Heidelberg, Mannheim, Germany; ${ }^{b}$ Departments of Neurology and \\ Rehabilitation, and the Center for Stroke and Neurocritical Care, International University of Health and Welfare \\ Atami Hospital, Atami, and ' Department of Cerebrovascular Medicine, National Cerebral and Cardiovascular \\ Center, Suita, Osaka, Japan; d Department of Neurology, Klinikum Frankfurt Höchst, Frankfurt, and ${ }^{\text {eDepartment }}$ \\ of Neurology, University of Heidelberg Hospital, Heidelberg, Germany; ${ }^{f}$ Department of Neurology, Federation of \\ National Public Service Personnel Mutual Aid Associations Tachikawa Hospital, Tokyo, Japan
}

\section{Key Words}

Acute stroke treatment - European stroke guidelines .

Evidence-based medicine $\cdot$ Ischemia $\cdot$ Japanese stroke guidelines · Randomized clinical trials · Review · Stroke prevention

\begin{abstract}
Background: Different aspects of acute stroke management and strategies for stroke prevention derive from two viewpoints: specific traditional and historical backgrounds and evidence-based medicine from modern randomized controlled trials (RCTs), meta-analysis and authorized clinical practice guidelines (GLs). Regarding stroke, GLs have been published by national and international organizations in different languages, most frequently in English. Cerebrovascular Diseases published the European GLs for the management of ischemic stroke and transient ischemic attacks in 2003 , with an update in 2008. At about the same time (in 2004), the first Japanese GLs for the management of stroke appeared in Japanese. The first English version of the updated Japanese GLs was published only in 2011 and included differently approved drugs and drug dosages as compared with other American or European countries. Methods:
\end{abstract}

Since 2011 , the authors have met repeatedly and have compared the latest versions of published European and Japanese GLs for ischemic and hemorrhagic strokes. Many aspects have only been addressed in one but left out in the other GLs, which consequently founded the basis for the comparison. Classification of evidence levels and recommendation grades defined by the individual committees differed between both original GLs. Results: Aspects of major importance were surprisingly similar and hence did not need extensive interpretation. Other aspects of ischemic stroke management differed significantly, e.g. the dosage of recombinant tissue plasminogen activator approved in Japan is lower $(0.6 \mathrm{mg} / \mathrm{kg})$ than in Europe $(0.9 \mathrm{mg} / \mathrm{kg})$, which derived from different practices in cardiovascular treatment prior to the design of acute ischemic stroke RCTs. Furthermore, comedication with neuroprotective agents (edaravone), intravenous anticoagulants (argatroban) or antiplatelet agents within 1-2 days after stroke onset is recommended in Japan but not in Europe. For cardioembolic stroke prevention, a major difference consists in a higher international normalized ratio target (2.0-3.0) in younger subjects versus in those $>70$ years $(1.6-2.6)$, without age restrictions

R.K and M.N. contributed equally to this work.

\section{KARGER}

E-Mail karger@karger.com

www.karger.com/ced
(C) 2013 S. Karger AG, Basel

1015-9770/13/0355-0402\$38.00/0
Dr. Rolf Kern

Department of Neurology

UniversitätsMedizin Mannheim, University of Heidelberg

Theodor-Kutzer-Ufer 1-3, DE-68167 Mannheim (Germany)

E-Mail kern@neuro.ma.uni-heidelberg.de 
in Europe. Conclusion: This brief survey - when compared with the lengthy original recommendations - provides a stimulating basis for an extended interest among Japanese and European stroke clinicians to learn from their individual experiences and to strengthen efforts for joint cooperation in treating and preventing stroke all around the globe.

Copyright $\odot 2013$ S. Karger AG, Basel

Reflecting the introduction of evidence-based medicine to clinical science, authorized clinical practice guidelines (GLs) regarding stroke have been published since 1994 by the American Heart Association (AHA), the Royal College of Physicians and the European Stroke Organization (ESO), for example. In Japan, evidence-based comprehensive GLs on cerebrovascular diseases were published in 2004 and 2009 from the Japan Stroke Society, but only in Japanese. In response to the request for the English version, considering the differences in race, stroke types, subtypes and drugs authorized, high morbidity and mortality of cerebrovascular disorders in Asian countries, which exceed those of myocardial infarction, and, also, the vast amount of untranslated Japanese literature, the English version of the entire Japanese GLs were first published in 2011 [1-7]. The purpose of this article is to compare the latest versions of the European and Japanese GLs for the management of ischemic stroke.

We compared the GLs, especially Recommendations of ESO GLs 2008 [8] and the 2009 update [9], with those of the Japanese GLs 2009 (English version in 2011 [1-7]). We tried to clarify the differences and similarities of both GLs and worked out which recommendations lacked in both GLs. Although Japanese GLs are comprehensive and even include asymptomatic cerebrovascular diseases and specific conditions which cause stroke and rehabilitation, for example, only those GLs relevant to the management of ischemic stroke were extracted from the entire chapters. For readers' convenience, 7 comparison tables were created, which integrate recommendations of both GLs for the management of ischemic stroke. Grades of recommendation of both GLs are shown and discussed in the Editorial.

\section{Management of Acute Ischemic Stroke}

\section{Referral and Patient Transfer}

GLs on prehospital care were described only in the European GLs. In Japan, official GLs on prehospital care were described in the 'neuroresuscitation GLs' (cochaired by Masao Nagayama and Hiroshi Okudera) by the Japan Resuscitation Council [10, English version in prep.]. Although there is little remarkable difference between both GLs, telemedicine was recommended in remote or rural areas in the European GLs (level B). Regarding the prehospital head positioning, Japanese neuroresuscitation GLs recommended to avoid the head-up position (class IIb) based on a study indicating that flat positioning improves blood flow velocity in acute ischemic stroke [11]. Regarding the prehospital stroke scale, both GLs did not recommend a specific scale, although Japanese GLs listed the Cincinnati Prehospital Stroke Scale, Los Angeles Prehospital Stroke Screen, Melbourne Ambulance Stroke Screen and Kurashiki Prehospital Stroke Scale as potential candidates (class IIa).

\section{Emergency Diagnostic Workup}

GLs on an emergency diagnostic workup were described only in the European GLs. In Japan, official GLs on this issue were described in the neuroresuscitation GLs [10]. There is little remarkable difference between both GLs. In the European GLs, the inclusion of diffusion-weighted imaging and $\mathrm{T} 2 *$-weighted gradient echo sequences was recommended if the required MRI device is available (level A). Japanese neuroresuscitation GLs strengthened the importance of screening acute cardiac diseases and aortic dissection (class I).

\section{Stroke Care Unit and Stroke Unit}

In the recent Helsingborg Declaration, acute organized stroke unit (SU) care was described as the backbone of the chain of care for all European stroke victims. In 2013, the ESO Stroke Unit Certification Committee defined evidence-based requirements for $\mathrm{SU}$ and announced the recommendations to establish a SU and Stroke Center [23]. On the other hand, in Japan, stroke care unit often refers to a ward in which advanced intensive care is provided to acute stroke patients in an unstable condition: in other words an intensive care unit specializing in stroke.

The SU signifies a ward in which a stroke team, which is composed of staff with different types of comedical skills, provides a constant and consistent range of therapies, including the treatment of acute phase stroke to rehabilitation; SUs are common in Europe. Both GLs recommended SUs (grade A, level A) for patients with all types of stroke (European GLs) or acute stroke excluding subarachnoid hemorrhage, lacunar infarction, deep coma and poor activities of daily living before onset (Japanese GLs; table 1). 
Table 1. General management of acute ischemic stroke

Japanese guidelines

Stroke care unit and SU
For patients with acute stroke, excluding subarachnoid hemorrhage, lacunar infarction, deep coma and poor activities of daily living before onset, treatment at a SU, which is a ward specializing in stroke and at which medical staff specialized in stroke systematically and prospectively perform intensive treatment and rehabilitation starting from an early stage under monitoring, can reduce the mortality and the duration of hospitalization, increase the rate of discharge for home care and improve the long-term activities of daily living and quality of life (grade A).

Management from the hyperacute to the acute phase of stroke

(1) General

(2) Respiration
(1) There is no scientific evidence that routine oxygen without obvious hypoxemia is useful (grade C2).

(2) Airway management and artificial respiratory management are desirable for patients with acute-phase stroke in whom a respiratory disorder is likely to cause any disturbance in consciousness (grade C1). administration to mild-to-moderate stroke patients
European guidelines (ESO)

(1) It is recommended that all stroke patients should be treated in a SU (class I, level A).

(2) It is recommended that healthcare systems ensure that acute stroke patients have access to high technology medical and surgical stroke care when required (class III, level B).
(3) Blood pressure

(1) The management of hypertension immediately after the onset of stroke can be initiated after a diagnosis of stroke subtype was made, except for the case where hypertensive encephalopathy or subarachnoid hemorrhage is highly suspected. Also, before using hypotensive drugs, it should be ascertained whether increased blood pressure could be due to pain, nausea or a full bladder. In contrast, marked hypotension (shock) should be promptly corrected with infusion and/or hypertensive drugs (grade $\mathrm{C} 1$ ).

(2) For acute-phase cerebral infarction, careful antihypertensive therapy is recommendable only when hypertension persists with a systolic blood pressure of $>220 \mathrm{~mm} \mathrm{Hg}$ or a diastolic blood pressure of $>120 \mathrm{~mm} \mathrm{Hg}$, or concurrent aortic dissection, acute myocardial infarction, heart failure or renal failure is present (grade C1).

(4) Glucose control, (1) Hyperglycemia or hypoglycemia should be corrected nutrition

\section{immediately (grade B).}

(2) Nutrition supplementation to ensure adequate calories and protein intake is recommendable for patients with malnutrition (grade B).
(1) Intermittent monitoring of neurological status, pulse, blood pressure, temperature and oxygen saturation is recommended for $72 \mathrm{~h}$ in patients with significant persisting neurological deficits (class IV, GCP).

(2) Regular monitoring of fluid balance and electrolytes is recommended in patients with severe stroke or swallowing problems (class IV, GCP).

(3) Normal saline $(0.9 \%)$ is recommended for fluid replacement during the first $24 \mathrm{~h}$ after stroke (class IV, GCP).

(4) It is recommended that oxygen should be administered if the oxygen saturation falls below $95 \%$ (class IV, GCP).

(1) Routine blood pressure lowering is not recommended following acute stroke (class IV, GCP).

(2) Cautious blood pressure lowering is recommended in patients with extremely high blood pressure $(>220 / 120$ $\mathrm{mm} \mathrm{Hg}$ ) on repeated measurements, or with severe cardiac failure, aortic dissection or hypertensive encephalopathy (class IV, GCP).

(3) It is recommended that abrupt blood pressure lowering be avoided (class II, level C).
(1) Monitoring serum glucose levels is recommended (class IV, GCP).

(2) Treatment of serum glucose levels $>180 \mathrm{mg} / \mathrm{dl}$ ( $>10$ $\mathrm{mmol} / \mathrm{l}$ ) with insulin titration is recommended (class IV, GCP).

(3) It is recommended that severe hypoglycemia [ $<50 \mathrm{mg} /$ $\mathrm{dl}(<2.8 \mathrm{mmol} / \mathrm{l})]$ should be treated with intravenous dextrose or infusion of 10-20\% glucose (class IV, GCP points).

(4) Oral dietary supplements are only recommended for nondysphagic stroke patients who are malnourished (class II, level B).

(5) Early commencement of nasogastric feeding (within $48 \mathrm{~h}$ ) is recommended in stroke patients with impaired swallowing (class II, level B).

(6) It is recommended that percutaneous enteral gastrostomy feeding should not be considered in stroke patients in the first 2 weeks (class II, level B). 
Table 1 (continued)

Japanese guidelines

European guidelines (ESO)

Management of For stroke, the incidence of complications during the acute complications acute phase, such as respiratory infection, urinary tract (1) General

infection, falling and skin injury, is generally high.
Complications are particularly frequent in patients who are dysfunctional before the onset, who have had a previous severe stroke or in elderly patients. The presence of complications not only raises the mortality rate but also causes deterioration of the functional outcome so that it is strongly recommendable to work on the prevention and treatment of complications (grade B).

\begin{tabular}{lll}
\hline (2) Infections & $\begin{array}{l}\text { It is recommendable to initiate vigorous physiotherapy or } \\
\text { respiratory rehabilitation during the acute phase to }\end{array}$ & $\begin{array}{l}\text { (1) Antibiotic prophylaxis is not recommended in } \\
\text { immunocompetent patients (class II, level B). }\end{array}$ \\
& $\begin{array}{ll}\text { (2) It is recommended that infections after stroke should } \\
\text { be treated with appropriate antibiotics (class IV, GCP). } \\
\end{array}$ & $\begin{array}{l}\text { (3) Prophylactic administration of antibiotics is not } \\
\text { recommended, and levofloxacin can be detrimental in } \\
\text { acute stroke patients (class II, level B). }\end{array}$
\end{tabular}

(3) Gastrointestinal Paying attention to concurrent gastrointestinal bleeding bleeding in the elderly patients and severe stroke patients, prophylactic intravenous administration of antiulcer agents $\left(\mathrm{H}_{2}\right.$ receptor antagonists) are recommended (grade $\mathrm{C} 1)$.

(4) Fever

(1) It is recommendable to use an antipyretic to lower the body temperature when the body temperature is elevated in patients with acute stroke (grade C1).

(2) No evidence currently exists indicating that therapeutic hypothermia is effective for acute stroke (especially cerebral infarction; grade $\mathrm{C} 1$ ).

(5) Falls/fractures

(1) It is recommended that the presence of pyrexia (temperature $>37.5^{\circ} \mathrm{C}$ ) should prompt a search for concurrent infection (class IV, GCP).

(2) Treatment of pyrexia (temperature $>37.5^{\circ} \mathrm{C}$ ) with paracetamol and fanning is recommended (class III, level C).

(1) An assessment of risk factors for falls is recommended for every stroke patient (class IV, GCP).

(2) Calcium/vitamin D supplements are recommended in stroke patients at risk of falls (class II, level B).

(3) Bisphosphonates (alendronate, etidronate and risedronate) are recommended in women with previous fractures (class II, level B).

(6) Urinary

incontinence

In stroke patients with urinary incontinence, specialist assessment and management is recommended (class III, level C).

Symptomatic therapy

(1) Seizure
(1) Seizure is an independent factor related to death during the acute phase. Prophylactic treatment for several days can be given to elderly patients with large hemorrhagic infarcts involving the cortex (grade C1). (2) Seizures are quite likely to happen again in patients who developed a seizure more than 14 days after onset and may well progress to symptomatic epilepsy; therefore, continuous treatment is recommendable (grade C1).
(1) Administration of anticonvulsants is recommended to prevent recurrent seizures after stroke (class I, level A). (2) Prophylactic administration of anticonvulsants to patients with recent stroke who have not had seizures is not recommended (class IV, GCP).

(2) Dysphagia

(1) It is preferable to perform a videofluoroscopic swallow examination for patients with possible dysphagia, but a water-swallowing test is useful as a simple screening test carried out at the bedside (grade B).

(2) When a patient is determined to be at a high risk for aspiration based on the test results, it is recommendable to consider an appropriate mode of delivering nourishment and prevention of aspiration (grade B).

Swallowing assessment is recommended but there are insufficient data to recommend a specific approach for treatment (class III, GCP).
Comparison of Stroke Guidelines:

Management of Ischemic Stroke 
Table 1 (continued)

(3) Headache Headache caused by stroke often disappears in a short period of time, but nonnarcotic analgesics can be used when the headache is severe (grade C1).

(4) Management of (1) Intravenous administration of hypertonic glycerol brain edema $\quad(10 \%)$ is recommended for large acute cerebral infarctions accompanying intracranial hypertension such as cardioembolic cerebral infarction and atherothrombotic infarction (grade B; the dosage depends on age and severity, but $10-12 \mathrm{ml} / \mathrm{kg}$ should be administered by fractionation over a few doses).

(2) The use of mannitol (20\%) can be considered in acute ischemic stroke, but no adequate scientific evidence currently exists (grade C1).

(3) Corticosteroids are not recommended because of a lack of clear scientific evidence showing their efficacy for acute ischemic stroke (grade C2).

(5) Prevention for deep venous thrombosis (DVT) and pulmonary embolism
(1) Subcutaneous injection of heparin or LMW heparin is recommended for the prevention of DVT and pulmonary embolism for patients with acute ischemic stroke with paralysis of the lower extremities. However, because there is a risk of intra- and extracranial hemorrhage, treatment cannot be recommended to be given routinely in patients with acute ischemic stroke (grade $\mathrm{C} 1$ ).

(2) Aspirin is not recommended for the prevention of pulmonary embolism in patients with acute ischemic stroke. The effect of dextran on DVT prevention has not been demonstrated (grade C2). There has not yet been sufficient scientific evidence that step-by-step compression stockings or intermittent pneumatic compression is effective for DVT prevention (grade C1).
It is recommended that osmotherapy can be used to treat elevated intracranial pressure prior to surgery if this is considered (class III, level C).
(1) Early rehydration and graded compression stockings are recommended to reduce the incidence of venous thromboembolism (class IV, GCP).

(2) Early mobilization is recommended to prevent complications such as aspiration pneumonia, DVT and pressure ulcers (class IV, GCP).

(3) It is recommended that low-dose subcutaneous heparin or LMW heparins should be considered for patients at high risk of DVT or pulmonary embolism (class I, level A).
Management from the Hyperacute to the Acute Phase of Stroke

Both European and Japanese GLs recommended the management of respiration, blood pressure and nutrition (table 1). Although there is little remarkable difference between both GLs, Japanese GLs specified it to the management during the hyperacute phase of stroke before the diagnosis of the stroke subtype, which might be better in terms of actual decision making in clinical practice. Thus, the Japanese GLs recommend that the management of hypertension immediately after the onset of stroke can be initiated after a diagnosis of the stroke subtype is finalized, except for cases highly suspicious of hypertensive encephalopathy or subarachnoid hemorrhage (grade C1). Both GLs were announced before the publication of the results of SCAST (the Scandinavian Candesartan Acute Stroke Trial) [12], which does not support blood pressure lowering in the acute phase of stroke associated with raised blood pressure, and the recommendations were similar in both GLs. Regarding nutritional management, European GLs were more detailed.

\section{Management of Acute Complications}

Both European and Japanese GLs described recommendations for complicated infections and fever (table 1). Additionally, European GLs made recommendations for falls or fractures and urinary incontinence, and Japanese GLs for gastrointestinal bleeding. Both GLs lacked recommendations for acute critical complications, e.g. acute respiratory failure, stunned myocardium, multiple organ failure, and convulsive and nonconvulsive status epilepticus.

\section{Symptomatic Therapy}

Both European and Japanese GLs described recommendations for seizure and dysphagia. Additionally, Japanese GLs provided recommendations for headache. Both GLs did not recommend specific anticonvulsants for acute or prophylactic treatment, although there is an increasingly 
wide selection of anticonvulsants. Regarding dysphagia, European GLs described that 'swallowing assessment is recommended but there are insufficient data to recommend a specific approach for treatment (Good Clinical Practice points, GCP)'. On the other hand, Japanese GLs described that 'it is preferable to perform a videofluoroscopic swallow examination in patients with possible dysphagia, but a water-swallowing test, which can be carried out at the bedside, may be useful as a simple screening test (grade B)'.

\section{Thrombolytic Therapy (Intravenous Administration)}

Regarding intravenous administration of a recombinant tissue plasminogen activator (rt-PA; alteplase), both European and Japanese GLs strongly recommended its use with many inclusion and exclusion criteria (grade A, level A; table 2). Japanese GLs differed from the European GLs in that:

(1) The therapeutic time window was still set at $\leq 3 \mathrm{~h}$ after onset, which was revised to $\leq 4.5 \mathrm{~h}$ in 2012 in the revised GLs on intravenous rt-PA therapy for acute stroke patients in Japan [13] (grade A). The earlier the administration of rt-PA is, the better the outcome, even within this therapeutic time window (grade A).

(2) The approved dose in Japan is $0.6 \mathrm{mg} / \mathrm{kg}$, because the J-ACT (Japan Alteplase Clinical Trial; a phase III clinical study) was performed using a $0.6 \mathrm{mg} / \mathrm{kg}$ dose [14] (grade A). In a postmarketing phase-IV trial in Japan (J-ACT II), the rates of recanalization and favorable outcome with $0.6 \mathrm{mg} / \mathrm{kg}$ i.v. rt-PA in patients with MR angiography-documented middle cerebral artery occlusion were comparable to those previously reported with the $0.9 \mathrm{mg} / \mathrm{kg}$ dose [15].

(3) The Japan Stroke Society has proposed and advised requirements for institutions that may perform intravenous rt-PA therapy.

(4) Intravenous infusion of low-dose $(60,000 \mathrm{U} /$ day) urokinase can be considered as treatment for patients with acute cerebral thrombosis (within 5 days) but in the absence of adequate scientific evidence (grade C1).

On the other hand, the target population of rt-PA is gradually expanding. European GLs recommended that intravenous rt-PA may also be administered in selected patients $<18$ and $>80$ years of age (level C). Also, in 2013, new GLs of AHA/American Stroke Association recommended that rt-PA may be considered in patients with mild stroke deficits, rapidly improving stroke symptoms, major surgery in the prior 3 months and recent myocardial infarction [16] (class IIb). In the revised GLs on intravenous rt-PA therapy for acute stroke patients in Japan [13], the criteria for target patients were revised and sev-

Comparison of Stroke Guidelines:

Management of Ischemic Stroke eral items of contraindication were deleted (e.g. prior ischemic stroke within 1-3 months before onset).

\section{Thrombolytic Therapy (Intra-Arterial}

\section{Administration)}

Both GLs recommended intra-arterial thrombolytic therapy for middle cerebral artery occlusion within $6 \mathrm{~h}$ after onset (grade B, level B), but with more specific inclusion criteria in Japanese GLs, such as embolic occlusion, moderate or less severe symptoms, no infarct or mild CT findings, and priority of the intravenous rt-PA therapy (table 2). Unlike Japanese GLs, European GLs recommended intra-arterial thrombolysis for acute basilar occlusion in selected patients (level B) and also intravenous thrombolysis for basilar occlusion as an acceptable alternative even after $3 \mathrm{~h}$ (level B). Because acute basilar occlusion is a very life-threatening condition, such recommendations would be critically important for physicians.

The revised GLs for appropriate treatment with intravenous rt-PA therapy in Japan [13] described that intraarterial local fibrinolytic therapy with urokinase for middle cerebral artery occlusion within $6 \mathrm{~h}$ after onset can improve outcome (grade B) based on the results of MELT (Middle Cerebral Artery Embolism Local Fibrinolytic Intervention Trial) in Japan [17]. Since both GLs were accomplished before the publication of randomized controlled trials (RCTs) on mechanical thrombectomy, no specific recommendations were given for this therapy.

\section{Anticoagulant Therapy in the Acute Stage}

European GLs clearly described that early administration of unfractionated heparin, low-molecular-weight (LMW) heparin or heparinoids is not recommended for the treatment of patients with acute ischemic stroke (class I, level A; table 2). Japanese GLs described that the use of heparin can be considered for cerebral infarction within $48 \mathrm{~h}$ after onset, but adequate scientific evidence is lacking (grade C1), and, also, the use of LMW heparin and heparinoid (neither of which are included in the Japanese healthcare insurance) for acute ischemic stroke can be considered, but adequate scientific evidence for either product is lacking (grade C1). These differences in GLs may partially reflect the favorable use of unfractionated heparin in patients with acute cardioembolic and progressing stroke in Japan before.

On the other hand, Japanese GLs recommended argatroban, a selective thrombin inhibitor developed in Japan, for cerebral infarction (excluding cardioembolic stroke) within $48 \mathrm{~h}$ after onset and with a maximum diameter of $\geq 1.5 \mathrm{~cm}$ (grade B) based on RCTs in Japan [18-20]. 
Table 2. Pharmacological treatment of acute ischemic stroke

\begin{tabular}{|c|c|}
\hline & Japanese guidelines \\
\hline $\begin{array}{l}\text { Thrombolytic } \\
\text { therapy } \\
\text { (intravenous } \\
\text { administration) }\end{array}$ & $\begin{array}{l}\text { (1) The intravenous administration of rt-PA (alteplase) is highly } \\
\text { recommended for patients with ischemic stroke who can be treated } \\
\text { within } 3 \mathrm{~h} \text { after onset (within } 4.5 \mathrm{~h} \text { in the revised guideline in } 2012 \\
\text { [13]) and who are carefully determined to be candidates (grade A). } \\
\text { In Japan, healthcare insurance is applicable to the intravenous } \\
\text { therapy with alteplase } 0.6 \mathrm{mg} / \mathrm{kg} \text {, and the exclusion criteria for the } \\
\text { determination of treatment and criteria for careful administration } \\
\text { are defined. In addition, the Japan Stroke Society has proposed and } \\
\text { advised requirements for institutions that may perform intravenous } \\
\text { rt-PA therapy. } \\
\text { (2) Intravenous administration of rt-PAs other than alteplase or } \\
\text { desmoteplase (not approved in Japan) is not recommendable because } \\
\text { it lacks adequate scientific evidence at present (grade C2). } \\
\text { (3) Intravenous infusion of low-dose ( } 60,000 \text { U/day) urokinase can } \\
\text { be considered as a treatment for patients with acute cerebral } \\
\text { thrombosis (within } 5 \text { days), but it has no adequate scientific } \\
\text { evidence (grade C1). } \\
\text { (4) Intravenous antihypertensive therapy is recommendable for } \\
\text { patients scheduled to receive thrombolytic therapy when the systolic } \\
\text { blood pressure is }>185 \mathrm{~mm} \mathrm{Hg} \text { or the diastolic blood pressure is } \\
\geq 110 \text { mm Hg (grade B). }\end{array}$ \\
\hline
\end{tabular}

Thrombolytic

therapy

(intraarterial

administration)
(1) For embolic occlusion of the middle cerebral artery with neurological deficits, selective transarterial local thrombolytic therapy is recommended for patients with moderate or less severe symptoms on arrival at the hospital without infarct lesion or with mild finding on CT, and in whom treatment can be started within $6 \mathrm{~h}$ after onset (grade B). However, it should be noted that intravenous rt-PA therapy is the first-line treatment for patients to whom drugs can be administered within $3 \mathrm{~h}$ after onset.

(2) There is no sufficient scientific evidence on local thrombolytic therapy (transarterial) during the acute stage for embolic occlusion in other regions or under other conditions (grade $\mathrm{C} 1$ ).

Anticoagulant (1) Argatroban, a selective thrombin inhibitor, is recommended for therapy in the cerebral infarction (excluding cardioembolic stroke) within acute stage

$48 \mathrm{~h}$ after onset and with a maximum diameter of $\geq 1.5 \mathrm{~cm}$ (grade B).
(2) The use of heparin can be considered for cerebral infarction within $48 \mathrm{~h}$ after onset, but adequate scientific evidence is lacking (grade $\mathrm{C} 1$ ).

(3) The use of low-molecular-weight heparin and heparinoid (neither of which are included under Japanese healthcare insurance) for acute ischemic stroke can be considered, but adequate scientific evidence for either product is lacking (grade C1).

\begin{tabular}{ll}
\hline Antiplatelet & (1) Intravenous infusion of ozagrel sodium $160 \mathrm{mg} /$ day is \\
therapy & recommendable for patients with acute cerebral thrombosis \\
in the acute stage & (cerebral infarction excluding cardioembolic stroke) within 5 days \\
& after onset (grade B). \\
& (2) Oral administration of aspirin $160-300 \mathrm{mg} / \mathrm{day}$ is \\
& recommendable for patients with acute cerebral infarction (within \\
& $48 \mathrm{~h}$; grade A).
\end{tabular}

Neuroprotective Edaravone, expected to display a neuroprotective effect, is agents recommendable for patients with acute cerebral infarction (thrombosis/embolism; grade B).

Hemodilution (1) Hemodilution therapy with a plasma expander can be therapy considered for the treatment of acute ischemic stroke, but adequate scientific evidence is lacking (grade C1).

(2) Hemodilution therapy with extracorporeal circulation can be considered for the treatment of acute ischemic stroke, but no adequate scientific evidence as yet exists (grade C1).
European guidelines (ESO)

(1) Intravenous rt-PA $(0.9 \mathrm{mg} / \mathrm{kg}$ body weight, maximum 90 $\mathrm{mg}$ ), with $10 \%$ of the dose given as a bolus followed by a 60 -min infusion, is recommended within $4.5 \mathrm{~h}$ of onset of ischemic stroke (class I, level A).

(2) The use of multimodal imaging criteria may be useful for patient selection for thrombolysis but is not recommended for routine clinical practice (class III, level C).

(3) It is recommended that blood pressures of $185 / 110 \mathrm{~mm} \mathrm{Hg}$ or higher is lowered before thrombolysis (class IV, GCP).

(4) It is recommended that intravenous rt-PA may be used in patients with seizures at stroke onset, if the neurological deficit is related to acute cerebral ischemia (class IV, GCP).

(5) It is recommended that intravenous rt-PA may also be administered in selected patients $<18$ years and $>80$ years of age, although this is outside the current European labeling (class III, level C).

(6) It is recommended that if thrombolytic therapy is planned or given, aspirin or other antithrombotic therapy should not be initiated within $24 \mathrm{~h}$ (class IV, GCP).

(1) Intra-arterial treatment of acute middle cerebral artery occlusion within a 6-hour time window is recommended as an option (class II, level B).

(2) Intra-arterial thrombolysis is recommended for acute basilar occlusion in selected patients (class III, level B).

Intravenous thrombolysis for basilar occlusion is an acceptable alternative even after $3 \mathrm{~h}$ (class III, level B).

Early administration of unfractionated heparin, LMW heparin or heparinoids is not recommended for the treatment of patients with acute ischemic stroke (class I, level A).
(1) It is recommended that aspirin (loading dose 160-325 mg) be given within $48 \mathrm{~h}$ after ischemic stroke (class I, level A).

(2) The use of other antiplatelet agents (single or combined) is not recommended in the setting of acute ischemic stroke (class III, level C).

(3) The administration of glycoprotein IIb-IIIa inhibitors is not recommended (class I, level A).

Currently, there is no recommendation to treat ischemic stroke patients with neuroprotective substances (class I, level A).

It is recommended that low blood pressure secondary to hypovolemia or associated with neurological deterioration in acute stroke should be treated with volume expanders (class IV, GCP). 
Table 3. Surgical and interventional treatment of acute ischemic stroke

Japanese guidelines

Decompressive surgery
(1) Decompressive craniectomy with a duraplasty within $48 \mathrm{~h}$ after onset is recommended for patients ${ }^{1}$ with a unilateral hemispheric infarction including the territory of the middle cerebral artery (grade A).

(2) Conservative treatment is recommended for cerebellar infarction when patients have clear consciousness and no hydrocephalus or brainstem compression is noted on CT imaging (grade $\mathrm{C} 1$ ).

In contrast, ventricular drainage is recommended for patients with hydrocephalus seen on CT and moderate disturbance of consciousness such as stupor due to hydrocephalus, but adequate scientific evidence is lacking (grade C1). Decompressive craniectomy is recommended for patients with brainstem compression seen on CT and severe disturbance of consciousness such as coma concomitantly with such CT findings; however, the scientific evidence regarding its efficacy is so far insufficient (grade $\mathrm{C} 1$ ).
Hypothermic (1) Hypothermic treatment can be considered to be instituted as a treatment treatment of acute ischemic stroke, but adequate scientific evidence is as yet unavailable (grade C1).

(2) The administration of normothermia therapy using an antipyretic can be considered for acute ischemic stroke, but the scientific evidence is currently inadequate (grade C1).
European guidelines (ESO)

(1) Surgical decompressive therapy within $48 \mathrm{~h}$ after symptom onset is recommended in patients $\leq 60$ years

of age with evolving malignant middle cerebral artery infarcts (class I, level A).

(2) It is recommended that ventriculostomy or surgical decompression be considered for treatment of large cerebellar infarctions that compress the brainstem (class III, level C).

\footnotetext{
${ }^{1}$ Specific criteria for eligibility are given in footnotes such as age, severity and duration of the neurological deficits and imaging characteristics.
}

\section{Antiplatelet Therapy in the Acute Stage}

Both GLs recommended aspirin for patients with acute cerebral infarction (within 48 h; grade A, level A). Japanese GLs recommended intravenous infusion of ozagrel sodium, an intravenous antiplatelet agent developed in Japan, $160 \mathrm{mg} /$ day for patients with acute cerebral thrombosis (cerebral infarction excluding cardioembolic stroke) within 5 days after onset (grade B) based on an RCT in Japan [21].

\section{Neuroprotective Agents}

Although European GLs described no recommendation for neuroprotective substances (level A), Japanese GLs recommended edaravone, an antioxidant developed in Japan, in patients with acute cerebral thrombosis and embolism (grade B) based on an RCT in Japan [22].

\section{Management of Brain Edema}

In Japan, hypertonic glycerol (10\%) is the standard treatment for suspected elevated intracranial pressure rather than mannitol, especially in nonsurgical settings. Recommendation grade was level $\mathrm{C}$ on osmotherapy in the European GLs, while it was grade B on hypertonic glycerol (10\%) for large acute cerebral infarctions in the
Japanese GLs. Both GLs did not describe any recommendations about hypertonic saline treatment.

\section{Hemodilution Therapy}

Low grade recommendation was made for hemodilution therapy by both European GLs (GCP) and Japanese GLs (grade C1).

\section{Prevention of Deep Venous Thrombosis and \\ Pulmonary Embolism}

Regarding pharmacological prevention of deep venous thrombosis and pulmonary embolism, European GLs strongly recommended low-dose subcutaneous heparin or LMW heparins for patients at high risk of either disease (level A). However, Japanese GLs described that these treatments cannot be recommended to be given routinely to patients with acute ischemic stroke considering the risk of intra- and extracranial hemorrhage (grade C1).

\section{Decompressive Surgery}

Both GLs recommended decompressive surgery for hemispheric infarction (grade A, level A) and for large cerebellar infarction (grade $\mathrm{C} 1$, level C) which fulfill the conditions (table 3 ). 
Table 4. Management of risk factors for primary prevention of ischemic stroke

Japanese guidelines

(1) Hypertension (1) Antihypertensive therapy is recommended for hypertensive patients (grade A).

(2) Recommended target blood pressure is $<140 / 90 \mathrm{~mm} \mathrm{Hg}$ for elderly patients, $<130 / 85 \mathrm{~mm} \mathrm{Hg}$ for young and middle-aged patients, and $<130 / 80 \mathrm{mmHg}$ for patients with concurrent DM or a renal disorder (grade A).

(3) As for the selection of antihypertensive drugs, Ca antagonists, diuretics, angiotensin-converting enzyme inhibitors and angiotensin II receptor blockers are recommended (grade A).

In particular, angiotensin-converting enzyme inhibitors and angiotensin II receptor blockers are recommended for patients with concurrent DM, chronic kidney disease, paroxysmal AF or heart failure, and evident left ventricular hypertrophy or left atrial enlargement (grade B).

(2) Diabetes mellitus

(1) Blood glucose control is recommended for DM patients (grade C1).

(2) Strict blood pressure control is advised for type 2 DM patients (grade A).

(3) Lipid control with administration of an HMG-CoA reductase inhibitor (statin) is recommended for type $2 \mathrm{DM}$ patients (grade A).
European guidelines (ESO)

(1) Blood pressure should be checked regularly. It is recommended that high blood pressure should be managed with lifestyle modification and individualized pharmacological therapy (class I, level A) aiming at normal levels of $120 / 80 \mathrm{~mm}$ $\mathrm{Hg}$ (class IV, GCP).

(2) For prehypertensive (120-139/80-90 mm Hg) patients with congestive heart failure, myocardial infarction, diabetes or chronic renal failure, antihypertensive mediation is indicated (class 1, level A).
(3) Dyslipidemia

Treatment with an HMG-CoA reductase inhibitor (statin) targeting low-density lipoprotein cholesterol is recommended for patients with dyslipidemia (grade A).
(4) Atrial

fibrillation
(1) Warfarin is highly recommended for patients with nonvalvular AF (NVAF) with at least 2 of any of the following risk factors: previous ischemic stroke or transient ischemic attack, concurrent congestive heart failure, hypertension, age $\geq 75$ years and DM (grade A). Warfarin is also recommended for NVAF patients with risk factors (grade B).

There is no sufficient evidence that aspirin (81-330 mg/day) or warfarin is effective for NVAF patients aged $<60$ years without risk factors (grade C1).

(2) Antiplatelet therapy may be administered to NVAF patients in whom warfarin is contraindicated (grade B).

(3) In general, the recommended intensity of warfarin therapy is a PT-INR of 2.0-3.0 (grade A).

For elderly (aged $\geq 70$ years) NVAF patients, a PT-INR of $1.6-2.6$ is recommended (grade B).
(1) Blood glucose should be checked regularly. It is recommended that diabetes should be managed with lifestyle modification and individualized pharmacological therapy (class IV, level C).

(2) In diabetic patients, high blood pressure should be managed intensively (class I, level A) aiming for levels $<130 / 80 \mathrm{~mm} \mathrm{Hg}$ (class IV, level C).

Where possible, treatment should include an angiotensin converting enzyme inhibitor or angiotensin receptor antagonist (class I, level A).

Blood cholesterol should be checked regularly. It is recommended that high blood cholesterol [e.g. low-density lipoprotein $>150 \mathrm{mg} / \mathrm{dl}(3.9 \mathrm{mmol} / \mathrm{l})$ ] should be managed with lifestyle modification (class IV, level C) and a statin (class I, level A).

(1) Aspirin may be recommended for patients with NVAF who are $<65$ years and free of vascular risk factors (class I, level A).

(2) Unless contraindicated, either aspirin or an oral anticoagulant (INR 2.0-3.0) is recommended for patients with NVAF who are aged $65-75$ years and free of vascular risk factors (class I, level A).

(3) Unless contraindicated, an oral anticoagulant (INR 2.0-3.0) is recommended for patients with NVAF aged $>75$ years, or who are younger but have risk factors such as high blood pressure, left ventricular dysfunction or DM (class I, level A). (4) It is recommended that patients with AF who are unable to receive oral anticoagulants should be offered aspirin (class I, level A).

(5) It is recommended that patients with $\mathrm{AF}$ who have mechanical prosthetic heart valves should receive long-term anticoagulation with a target INR based on the prosthesis type, but not less than INR 2-3 (class II, level B).

It is recommended that cigarette smoking be discouraged (class III, level B).
(5) Smoking

(1) Smoking is a risk factor for ischemic stroke and subarachnoid hemorrhage. Smoking cessation is recommended for smokers (grade A).

(2) Passive smoking may be a risk factor for stroke; thus, passive smoking should be avoided (grade $\mathrm{C} 1$ ).

(3) Education for cigarette smoking cessation, nicotine replacement therapy and oral smoking cessation medications are recommendable for smokers (grade B).

\begin{tabular}{ll}
\hline $\begin{array}{l}\text { (6) Alcohol } \\
\text { consumption }\end{array}$ & Heavy drinking should be avoided to prevent stroke (grade A). \\
\hline $\begin{array}{l}\text { (7) Metabolic } \\
\text { syndrome }\end{array}$ & $\begin{array}{l}\text { The metabolic syndrome is a risk factor for ischemic stroke. Treatment } \\
\text { to reduce body weight to an appropriate level and improve lifestyle } \\
\text { with physical exercise and diet as the basis and, when necessary, drug } \\
\text { therapy according to each component are recommended (grade B). }\end{array}$ \\
&
\end{tabular}

It is recommended that heavy use of alcohol be discouraged (class III, level B).

Subjects with an elevated body mass index are recommended to follow a weight-reducing diet (class III, level B). 


\section{Hypothermic Treatment}

Hypothermic treatment was described in both GLs with recommendation grade C1 and GCP (table 3). Considering the actual clinical practice, we might need specific GLs for very severe forms of acute ischemic stroke.

\section{Recommendations Mentioned in Only One of the Guidelines}

In addition, the Japanese GLs give statements regarding fibrinogen lowering therapy, hyperbaric treatment, emergency carotid endarterectomy/acute revascularization of the carotid artery, and on the management of special conditions such as arterial dissection, aortic dissection and cerebral venous occlusion. GLs on the management of transient ischemic attacks are different regarding their content. The European GLs focus on recommendations on the diagnostic work-up, while mainly the therapeutic management is described in the Japanese GLs.

\section{Primary Prevention of Ischemic Stroke}

\section{Public Awareness and Education}

The European GLs recommended educational programs to increase the awareness of stroke at population level and among professionals (level B).

Management of Vascular Risk Factors for Stroke Hypertension. Both GLs recommended regular blood pressure control and the management of elevated blood pressure with lifestyle modification and pharmacotherapy (grade A, level A). Japanese GLs gave more detailed advice for specific drugs to be preferred for hypertensive individuals with and without diabetes mellitus (DM) and chronic kidney disease, for example (table 4). However, both GLs favored the use of an angiotensin-converting enzyme inhibitor or an angiotensin receptor blocker for blood pressure control in patients with DM (grade B, level A), aiming at blood pressure levels $<130 / 80 \mathrm{~mm} \mathrm{Hg}$ (grade A, level C). Recommendations for target blood pressure were mainly based on GLs from the Japanese Society of Hypertension 2009, European Society of Hypertension and European Society of Cardiology 2007 [24, 25].

Diabetes Mellitus. Both GLs recommended regular blood glucose control and management of elevated blood glucose, especially in patients with DM (grade A, level A). Japanese GLs additionally emphasized the importance of lipid control with administration of an HMG-CoA reduc-

Comparison of Stroke Guidelines:

Management of Ischemic Stroke tase inhibitor (statin) in patients with type $2 \mathrm{DM}$ according to a meta-analysis (grade A) [26].

Dyslipidemia. Both GLs unequivocally recommended lipid control with statins for patients with dyslipidemia (grade A, level A).

Atrial Fibrillation. Both GLs recommended an oral anticoagulant for primary prevention of stroke in patients with atrial fibrillation (AF) aged $\geq 75$ years and/or the presence of risk factors such as high blood pressure, congestive heart failure or DM (grade A, level A). According to the Japanese GLs, antiplatelet therapy may only be considered for AF patients in whom oral anticoagulants are contraindicated (grade B). This recommendation is based on the results of the Japan Atrial Fibrillation Stroke Study [27]. In contrast, European GLs state that 'aspirin may be recommended for patients with non-valvular AF who are younger than 65 years and free of vascular risk factors' (class I, level A). According to the results of the Japanese Nonvalvular Atrial Fibrillation-Embolism Secondary Prevention Cooperative Study Group and other studies [28-31], a lower intensity of warfarin therapy with a prothrombin time (PT)-international normalized ratio (INR) of 1.6-2.6 in elderly patients aged $\geq 75$ years was recommended in Japan (grade B) instead of the general recommendation of a PT-INR of 2.0-3.0 for patients $<75$ years and all patients in Europe (grade A, level A). Since both GLs were published before the RCTs on new oral anticoagulants, no specific recommendations were given for these drugs.

Smoking. Both GLs recommended that cigarette smoking should be discouraged or cessation of smoking for smokers (grade A, level B). The Japanese GLs gave more specific recommendations on passive smoking and education for smoking cessation.

Alcohol Consumption. Both GLs recommended that heavy drinking should be avoided (grade A, level B).

Sleep Apnea Syndrome. For primary prevention, only the Japanese GLs recommended the treatment of the sleep apnea syndrome according to individual clinical conditions (grade $\mathrm{C} 1$ ).

Metabolic Syndrome/Obesity. Both GLs recommended specific measures for weight reduction and improvement in lifestyle (grade B, level B).

Chronic Kidney Disease. The management of chronic kidney disease as a predictor of stroke was discussed in the Japanese GLs only: lifestyle improvement, and blood pressure and blood glucose control were recommended at a high level of evidence.

Unclassified Factors. Some additional statements were made in the European GLs without correspondence in the Japanese GLs: GLs recommended regular physical ac- 
tivity (level B) and 'healthy' nutrition (level B), while hormone replacement therapy and antioxidant vitamin supplements were not recommended (level A).

\section{Antiplatelet Therapy for Primary Prevention/Carotid Stenosis}

The European GLs gave specific recommendations for antiplatelet therapy for primary prevention and for the management of asymptomatic carotid stenosis. In brief, the GLs stated that there is no evidence for the use of aspirin (level A) or other antiplatelet agents (GCP) for primary prevention of ischemic stroke. Aspirin, however, was recommended for patients with asymptomatic carotid stenosis $>50 \%$ 'to reduce their risk of vascular events' (level B), and before and after carotid surgery (level A) [32-34]. According to the European GLs, carotid surgery is 'not recommended for asymptomatic individuals with significant carotid stenosis (NASCET 60-99\%), except in those at high risk of stroke' (level C). Carotid angioplasty, with or without stenting, was 'not recommended for patients with asymptomatic carotid stenosis' (GCP). Similarly, Japanese GLs indicated that 'for asymptomatic severe carotid stenosis, in addition to the best medical treatment including antiplatelet therapy, CEA is only recommended to be performed by appropriate surgeons and at facilities experienced with surgery and perioperative management (grade B)'.

\section{Secondary Prevention of Ischemic Stroke}

\section{Management of Vascular Risk Factors}

Hypertension. Similar to primary prevention, both GLs clearly recommended regular blood pressure control and antihypertensive treatment of elevated blood pressure for the prevention of recurrent stroke after the acute phase (grade A, level A; table 5).

Diabetes Mellitus. Both GLs recommended regular blood glucose control and management of elevated blood glucose for the prevention of recurrent cerebral infarction (grade C1, GCP). For patients with type $2 \mathrm{DM}$ who do not need insulin, treatment with pioglitazone was recommended after stroke (grade B, level B).

Dyslipidemia. Both GLs strongly recommended highdose statins in patients with noncardioembolic stroke (grade B, level A). Japanese GLs also recommended the combination of low-dose statins with eicosapentaenoic acid for the prevention of recurrent stroke in patients who are being treated for dyslipidemia (grade B) as such a combination was demonstrated to reduce the risk of recurrent stroke in Japanese patients [35].
Atrial Fibrillation. Both GLs recommended an oral anticoagulant for secondary prevention of stroke in patients with AF (grade A, level A) except for those 'with comorbid conditions such as falls, poor compliance, uncontrolled epilepsy, or gastrointestinal bleeding' (level C, European GLs). A lower intensity of warfarin therapy with a PT-INR of 1.6-2.6 in elderly patients aged $\geq 75$ years was recommended in Japan (grade B) instead of the general recommendation of a PT-INR of 2.0-3.0 for patients $<75$ years and all patients in Europe (grade A, level A).

Smoking. Both GLs recommended cessation of smoking for smokers or that cigarette smoking should be discouraged (grade A, level C) although there are no adequate data as to whether or not it decreases the recurrence rate (grade $\mathrm{C} 1$ ).

Alcohol Consumption. Both GLs recommended that heavy drinking should be avoided (grade C1, GCP). The Japanese GLs stated that 'drinking more than a moderate amount of alcohol increases the frequency of cerebral infarction, but a small amount of drinking decreases the incidence of cerebral infarction' (grade A) [36].

Sleep Apnea Syndrome. For secondary prevention, only the European GLs recommended the treatment of the sleep apnea syndrome with continuous positive airway pressure breathing, at a low level of evidence (GCP).

Metabolic Syndrome/Obesity. The European GLs recommended a weight-reducing diet for subjects with elevated body mass index although there are no specific data in secondary prevention (level C). The Japanese GLs stated that there is 'a lack of scientific evidence as to whether or not control of the metabolic syndrome is effective for secondary prevention (grade $\mathrm{C} 1$ ).

\section{Antiplatelet Therapy for Secondary Prevention}

Noncardioembolic Stroke. Antiplatelet therapy for the prevention of noncardioembolic stroke was recommended in both GLs with a high level of evidence (grade A, level A). In Europe, combination treatment with aspirin and dipyridamole [37, 38] or clopidogrel alone [39], alternatively aspirin or triflusal [40] alone, were considered first choice; the combination of aspirin and clopidogrel [41] was not recommended (level A). In Japan, aspirin (grade A), clopidogrel (grade A), cilostazol (grade B) [42-44] or ticlopidine (grade B) were considered first choice. The combination therapy with aspirin and dipyridamole was not recommended, partly reflecting the unavailability of sustained-release dipyridamole in Japan to date (table 6).

Cardioembolic Stroke. Japanese GLs specified that oral anticoagulants represent the first-line treatment for the secondary prevention of cardioembolic stroke (level A) 
Table 5. Management of risk factors for secondary prevention of ischemic stroke

\begin{tabular}{lll}
\hline & Japanese guidelines & European guidelines (ESO) \\
$\begin{array}{l}\text { (1) } \\
\text { Hypertension }\end{array}$ & $\begin{array}{l}\text { Antihypertensive treatment is recommended for prevention } \\
\text { of recurrent cerebral infarction. The target blood pressure is } \\
\text { defined as }<140 / 90 \mathrm{~mm} \mathrm{Hg} \text { (grade A). }\end{array}$ & $\begin{array}{l}\text { It is recommended that blood pressure be checked regularly. } \\
\text { Blood pressure lowering is recommended after the acute } \\
\text { phase, including in patients with normal blood pressure } \\
\text { (class I, level A). }\end{array}$ \\
$\begin{array}{lll}\text { (2) Diabetes } \\
\text { mellitus }\end{array}$ & $\begin{array}{l}\text { (1) Blood glucose control is recommended for prevention of } \\
\text { recurrent cerebral infarction (grade C1). } \\
\text { (2) The treatment of DM with pioglitazone, a drug } \\
\text { improving insulin resistance, is effective for the prevention } \\
\text { of recurrent cerebral infarction (grade B). }\end{array}$ & $\begin{array}{l}\text { (1) is recommended that blood glucose should be checked } \\
\text { regularly. It is recommended that diabetes should be } \\
\text { panaged with lifestyle modification and individualized } \\
\text { pharmacological therapy (class IV, GCP). } \\
\text { (2) In patients with type 2 diabetes who do not need insulin, } \\
\text { treatment with pioglitazone is recommended after stroke } \\
\text { (class III, level B). }\end{array}$ \\
\hline
\end{tabular}
(3)
Dyslipidemia
(1) Dyslipidemia control is recommended for the prevention
of recurrent cerebral infarction (grade $\mathrm{C} 1$ ).
(2) High-dose statins are effective for the prevention of
recurrent cerebral infarction (grade B).
(3) Low-dose statins in combination with eicosapentaenoic acid are effective for the prevention of recurrent stroke in patients who are being treated for dyslipidemia (grade B).

(1) Statin therapy is recommended in subjects with
noncardioembolic stroke (class I, level A).

(4) Atrial (1) Warfarin is effective for the secondary prevention in fibrillation cerebral infarction patients with NVAF. In general, it is recommended to control it within the PT-INR range of 2.0-3.0 (grade A).

(2) For patients with cerebral infarction or transient ischemic attack aged $\geq 70$ years with NVAF, slightly low doses (PT-INR 1.6-2.6) are recommended (grade B), and it is advised not to exceed a PT-INR of 2.6 to avoid bleeding complications (grade B).

\begin{tabular}{ll}
\hline (5) Smoking & $\begin{array}{l}\text { Smoking cessation decreases the incidence of cerebral } \\
\text { infarction (grade A), but there are no adequate data as to } \\
\text { whether or not it decreases the recurrence rate (grade C1). }\end{array}$
\end{tabular}

(6) Alcohol Drinking more than a moderate amount of alcohol increases consumption the frequency of cerebral infarction, but a small amount of drinking decreases the incidence of cerebral infarction (grade A).

Nonetheless, there is no adequate scientific evidence as to whether or not a small amount of alcohol consumption reduces the recurrence rate (grade $\mathrm{C} 1$ ).

(7) Metabolic The metabolic syndrome based on visceral obesity is a risk syndrome/ factor for cerebral infarction. However, there is a lack of obesity scientific evidence as to whether or not metabolic syndrome control is effective for secondary prevention (grade C1).
(1) Oral anticoagulation (INR 2.0-3.0) is recommended after ischemic stroke associated with AF (class I, level A). (2) Oral anticoagulation is not recommended in patients with comorbid conditions such as falls, poor compliance, uncontrolled epilepsy or gastrointestinal bleeding (class III, level C).

Increasing age alone is not a contraindication to oral anticoagulation (class I, level A).

It is recommended that cigarette smoking be discouraged (class III, level C).

It is recommended that heavy use of alcohol be discouraged (class IV, GCP).

Subjects with an elevated body mass index are recommended to adopt a weight-reducing diet (class IV, level C). while antiplatelet drugs should be administered only if oral anticoagulants are contraindicated.

\section{Anticoagulant Therapy}

As stated above, both GLs recommended an oral anticoagulant for the secondary prevention of stroke in AF patients (grade A, level A), except for those 'with comorbid conditions such as falls, poor compliance, uncon- trolled epilepsy, or gastrointestinal bleeding' (level C, European GLs; table 6). European GLs did not generally recommend anticoagulation after cardioembolic stroke unrelated to AF except for specific conditions (GCP) or a high risk of recurrence (level C). Japanese GLs recommended anticoagulation at a PT-INR of 2.0-3.0 for patients with rheumatic heart disease, dilated cardiomyopathy and mechanical prosthetic valves (grade A). In addi- 
Table 6. Pharmacological therapy for secondary prevention of ischemic stroke

\begin{tabular}{|c|c|c|}
\hline & Japanese guidelines & European guidelines (ESO) \\
\hline $\begin{array}{l}\text { Antiplatelet } \\
\text { therapy }\end{array}$ & $\begin{array}{l}\text { (1) Administration of antiplatelet therapy is recommended for the } \\
\text { secondary prevention of noncardioembolic stroke (grade A). } \\
\text { (2) The most effective antiplatelet therapy (available in Japan) for the } \\
\text { secondary prevention of noncardioembolic stroke at present is either } \\
\text { aspirin } 75-150 \mathrm{mg} \text { /day clopidogrel } 75 \mathrm{mg} / \text { day (grade A), cilostazol } \\
200 \mathrm{mg} / \text { day, or ticlopidine } 200 \mathrm{mg} / \text { day (grade B). } \\
\text { (3) Antiplatelet therapy is recommended for the secondary } \\
\text { prevention of lacunar stroke (grade B), with adequate blood pressure } \\
\text { control. } \\
\text { (4) For the secondary prevention of cardioembolic stroke, the } \\
\text { first-line drugs are generally not antiplatelet agents, but the } \\
\text { anticoagulant warfarin (grade A). } \\
\text { Antiplatelet drugs such as aspirin should be administered only to } \\
\text { patients in whom warfarin is contraindicated (grade B). }\end{array}$ & $\begin{array}{l}\text { (1) It is recommended that patients receive antithrombotic } \\
\text { therapy (class I, level A). } \\
\text { (2) It is recommended that patients not requiring anticoagulation } \\
\text { should receive antiplatelet therapy (class I, level A). } \\
\text { Where possible, combined aspirin and dipyridamole, or } \\
\text { clopidogrel alone, should be given. Alternatively, aspirin alone, or } \\
\text { triflusal alone, may be used (class I, level A). } \\
\text { (3) The combination of aspirin and clopidogrel is not } \\
\text { recommended in patients with recent ischemic stroke, except in } \\
\text { patients with specific indications (e.g. unstable angina or } \\
\text { non-Q-wave myocardial infarction or recent stenting); treatment } \\
\text { should be given for up to } 9 \text { months after the event (class I, level A). } \\
\text { (4) It is recommended that patients who have a stroke on } \\
\text { antiplatelet therapy should be reevaluated for pathophysiology } \\
\text { and risk factors (class IV, GCP). }\end{array}$ \\
\hline
\end{tabular}

\section{Anti-}

coagulant

therapy
(1) Warfarin is the first-line medication for secondary prevention of cardioembolic stroke or transient ischemic attack with NVAF, and it is recommended to maintain the PT-INR at $2.0-3.0$ (grade A). A PT-INR of $1.6-2.6$ is recommended for those aged $\geq 70$ years (grade B). Hemorrhagic complications sharply increase with a PT-INR $\geq 2.6$ (grade B).

(2) For patients with heart diseases such as rheumatic heart disease and dilated cardiomyopathy, maintenance at a PT-INR of $2.0-3.0$ is recommended (grade A).

(3) For patients with mechanical prosthetic valves, it is recommended to avoid a PT-INR below 2.0 - 3.0 (grade A) (4) Approximate timing of starting warfarin may be within 2 weeks after the onset of cerebral infarction. However, warfarin initiation needs to be delayed in patients with a large infarction, poor blood pressure control and bleeding tendency (grade $\mathrm{C} 1$ ).

(5) Aspirin is indicated for patients in whom warfarin is contra-indicated, but its effect is clearly inferior to that of warfarin (grade B).

(6) Oral administration of warfarin is desirably continued when performing procedures or minor surgery (such as tooth extraction) during which bleeding can be easily managed. When conducting gastrointestinal endoscopic examination/treatment, warfarin needs to be interrupted for 3 - 4 days. During the interruption of warfarin for $4-5$ days or less in patients at lower risk of thrombosis or embolism, bridge therapy with heparin, for example, is not usually employed. For patients at higher risk of thrombosis or embolism, drip infusion to avoid dehydration and heparin (bridge therapy) may be employed considering the patient's condition (grade C1 for these).
(1) Oral anticoagulation (INR 2.0 - 3.0) is recommended after ischemic stroke associated with AF (class I, level A). Oral anticoagulation is not recommended in patients with comorbid conditions such as falls, poor compliance, uncontrolled epilepsy or gastrointestinal bleeding (class III, level C). Increasing age alone is not a contraindication to oral anticoagulation (class I, level A).

(2) It is recommended that patients with cardioembolic stroke unrelated to AF should receive anticoagulants (INR 2.0 - 3.0) if the risk of recurrence is high (class III, level C).

(3) It is recommended that anticoagulation should not be used after noncardioembolic ischemic stroke, except in some specific situations, such as aortic atheromas, fusiform aneurysms of the basilar artery, cervical artery dissection or patent foramen ovale in the presence of proven deep vein thrombosis or atrial septal aneurysm (class IV, GCP).

(4) It is recommended that combined low-dose aspirin and dipyridamole should be given if oral anticoagulation is contraindicated (class IV, GCP). tion, Japanese GLs gave specific advice regarding timing of the start of oral anticoagulation after stroke and regarding interruption of oral anticoagulation for performing medical procedures or surgery based on the GLs of the Japanese Circulation Society [45].

\section{Cerebral Circulation and Metabolism Enhancers}

Japanese GLs gave a weak recommendation (grade B) for the cerebral circulation and metabolism enhancers, such as ibudilast, nicergoline and ifenprodil tartrate to be used 'only after full consideration of their indications based on the signs and symptoms of each patient'.

\section{Antidepressants}

Both GLs recommend drug therapy (and interventions without drugs) to improve mood on poststroke depressive states (grade A, level A). Japanese GLs specifically mentioned selective serotonin reuptake inhibitors as drugs of choice.

\section{Carotid Endarterectomy}

Both GLs recommended carotid endarterectomy (CEA) for patients with symptomatic severe $(\geq 70 \%)$ stenosis of the internal carotid artery (class I, level A), to be performed by the appropriate surgeons and at experienced facilities 
Table 7. Surgical and interventional therapy for secondary prevention of ischemic stroke

\begin{tabular}{|c|c|c|}
\hline & Japanese guidelines & European guidelines (ESO) \\
\hline $\begin{array}{l}\text { Endovascular } \\
\text { therapy }\end{array}$ & $\begin{array}{l}\text { (1) Carotid artery stenting is recommended for patients with } \\
\text { internal carotid stenosis who have risk factors (grade B). } \\
\text { (2) Carotid artery stenting can be considered for patients with } \\
\text { internal carotid stenosis who have no risk factor for CEA, but } \\
\text { adequate scientific evidence for this approach is lacking (grade } \\
\text { C1). } \\
\text { (3) There is no adequate scientific evidence for performing } \\
\text { angioplasty/stenting for extra-/intracranial artery stenosis } \\
\text { excluding the cervical carotid artery (grade C1). }\end{array}$ & $\begin{array}{l}\text { (1) Carotid percutaneous transluminal angioplasty and/or carotid } \\
\text { artery stenting is only recommended in selected patients (class I, } \\
\text { level A). } \\
\text { It should be restricted to the following subgroups of patients with } \\
\text { severe symptomatic carotid artery stenosis: those with } \\
\text { contra-indications to CEA, stenosis at a surgically inaccessible site, } \\
\text { restenosis after earlier CEA, and stenosis after radiotherapy (class } \\
\text { IV, GCP). } \\
\text { Patients should receive a combination of clopidogrel and aspirin } \\
\text { immediately before and for at least } 1 \text { month after stenting (class IV, } \\
\text { GCP). } \\
\text { (2) It is recommended that endovascular treatment may be } \\
\text { considered in patients with symptomatic intracranial stenosis } \\
\text { (class IV, GCP). }\end{array}$ \\
\hline $\begin{array}{l}\text { Endovascular } \\
\text { closure of } \\
\text { patent foramen } \\
\text { ovale }\end{array}$ & $\begin{array}{l}\text { (1) Surgical closure and percutaneous transcatheter closure of } \\
\text { the foramen ovale may be considered for the prevention of } \\
\text { patent foramen ovale-mediated recurrent paradoxical cerebral } \\
\text { embolisms (grade C1). } \\
\text { (2) Percutaneous transcatheter occlusion may be considered for } \\
\text { the prevention of recurrent paradoxical cerebral embolisms } \\
\text { associated with a pulmonary arteriovenous fistula (grade C1). }\end{array}$ & $\begin{array}{l}\text { It is recommended that endovascular closure of a patent foramen } \\
\text { ovale may be considered in patients with cryptogenic stroke and } \\
\text { high-risk patent foramen ovale (class IV, GCP). }\end{array}$ \\
\hline
\end{tabular}

(table 7). Recommendations were less certain for moderate (50-69\%) stenosis (grade B, level A). CEA was not recommended for stenosis $<50 \%$ according to European GLs (level A). However, according to Japanese GLs, CEA could be considered in the presence of vulnerable plaques and/ or ulceration at a low level of evidence (grade C1).

\section{Endovascular Therapy}

Both GLs recommended carotid artery stenting only under certain conditions (grade B, level A), in particular high-grade stenosis, risk factors for CEA, surgically inaccessible sites, restenosis after CEA or stenosis following radiation. Intracranial stenting was not recommended (grade C1, GCP).

\section{Extracranial-Intracranial Bypass}

Japanese GLs gave a weak recommendation that extracranial-intracranial bypass surgery may be considered with a symptomatic internal carotid artery and middle cerebral artery occlusion/stenosis (grade B). However, this recommendation was made before publication of the COSS (Carotid Occlusion Surgery Study) trial comparing extracranial-intracranial bypass surgery with best medical treatment [46]. 
Endovascular Closure of a Patent Foramen Ovale

Both GLs stated that endovascular closure of a patent foramen ovale can be considered in patients with cryptogenic stroke and either high-risk patent foramen ovale (European GLs, GCP) or recurrent paradoxical cerebral embolism (Japanese GLs, grade C1). It should be noted that the GLs were published before RCTs comparing endovascular closure with medical treatment.

\section{Conclusions}

This article summarizes similarities and differences between Japanese and European GLs for the management of ischemic stroke published between 2008 and 2011. Although there are obvious differences between the GLs regarding structure, length and categorization of the level of evidence, the vast majority of recommendations is largely similar. However, there are some interesting differences between the GLs.

For the management of acute ischemic stroke, the most important difference is the dosage of intravenous rt-PA: the approval in Japan envisages a lower dose of 0.6 $\mathrm{mg} / \mathrm{kg}$, while in Europe a dose of $0.9 \mathrm{mg} / \mathrm{kg}$ is used. The Japanese GLs recommend the selective thrombin inhibitor argatroban for noncardioembolic stroke within $48 \mathrm{~h}$ after onset. In Europe, early administration of unfractionated heparin, LMW heparin and heparinoids is generally not recommended. During the acute stage, Japanese GLs propose intravenous infusion of the antiplatelet agent ozagrel sodium for noncardioembolic stroke, a drug not well known and not approved in Europe. In addition, the Japanese GLs recommend the antioxidant edaravone, while in Europe administration of neuroprotective agents are generally not recommended.
For primary and secondary prevention of ischemic stroke, one of the major differences is the dosage of oral anticoagulants for stroke prevention in elderly patients with AF. For patients aged $\geq 75$ years, a target PT-INR of 1.6-2.6 is recommended in Japan instead of 2.0-3.0 for younger patients: In Europe, no specific INR adaptation according to age was provided. For treatment of dyslipidemia in the secondary prevention of stroke, Japanese GLs also allow a combination of eicosapentaenoic acid with low-dose statins as an alternative to the standard treatment with high-dose statins. Finally, the drug cilostazol has been investigated extensively and is approved for the secondary prevention of ischemic stroke in Japan as an alternative to aspirin or clopidogrel.

Some new relevant aspects of stroke management have emerged during the last years, such as interventional thrombectomy, intracranial stenting, extra-/intracranial bypass surgery and stroke prevention with new oral anticoagulants. As the GLs discussed in this article have been announced before publication of trials investigating these treatment strategies, specific recommendations are still lacking. Their inclusion will be a major task for the next upcoming European and Japanese GLs on stroke management.

\section{Acknowledgments}

We would like to thank all Members, Staff and the Reviewers of the Joint Committee on Guidelines for the Management of Stroke for the English version, especially Prof. Shotai Kobayashi, the Group Leader of the Chapter 'Stroke in General' and Prof. Kazuo Minematsu, the Group Leader of the Chapter 'Cerebral Infarction/TIA' of the Japanese GLs, and also, Ms. Akiko Tsuchida (Academic Research Communications, Toyama, Japan) for her professional assistance in the preparation of the tables.

\section{References}

1 Shinohara Y, Yanagihara T, Abe K, Yoshimine $T$, Fujinaka T, Chuma T, Ochi $F$, Nagayama M, Ogawa A, Suzuki N, Katayama Y, Kimura A, Kobayashi S: I. Stroke in general. J Stroke Cerebrovasc Dis 2011;20(suppl 1):S7-S30.

2 Shinohara Y, Yanagihara T, Abe K, Yoshimine T, Fujinaka T, Chuma T, Ochi F, Nagayama M, Ogawa A, Suzuki N, Katayama Y, Kimura A, Kobayashi S: II. Cerebral infarction/transient ischemic attack (TIA). J Stroke Cerebrovasc Dis 2011;20(suppl 1):S31-S73.
- 3 Shinohara Y, Yanagihara T, Abe K, Yoshimine $T$, Fujinaka T, Chuma T, Ochi $F$, Nagayama M, Ogawa A, Suzuki N, Katayama Y, Kimura A, Kobayashi S: III. Intracerebral hemorrhage. J Stroke Cerebrovasc Dis 2011. 20(suppl 1):S74-S99.

4 Shinohara Y, Yanagihara T, Abe K, Yoshimine $\mathrm{T}$, Fujinaka $\mathrm{T}$, Chuma $\mathrm{T}$, Ochi $\mathrm{F}$, Nagayama M, Ogawa A, Suzuki N, Katayama Y, Kimura A, Kobayashi S: IV. Subarachnoid hemorrhage. J Stroke Cerebrovasc Dis 2011; 20(suppl 1):S100-S115.
5 Shinohara Y, Yanagihara T, Abe K, Yoshimine T, Fujinaka T, Chuma T, Ochi F, Nagayama M, Ogawa A, Suzuki N, Katayama Y, Kimura A, Kobayashi S: V. Asymptomatic cerebrovascular diseases. J Stroke Cerebrovasc Dis 2011;20(suppl 1):S116-S128.

- 6 Shinohara Y, Yanagihara T, Abe K, Yoshimine $T$, Fujinaka T, Chuma T, Ochi $F$, Nagayama M, Ogawa A, Suzuki N, Katayama Y, Kimura A, Kobayashi S: VI. Other types of cerebrovascular disorders. J Stroke Cerebrovasc Dis 2011;20(suppl 1):S129-S144. 
7 Shinohara Y, Yanagihara T, Abe K, Yoshimine T, Fujinaka T, Chuma T, Ochi F, Nagayama M, Ogawa A, Suzuki N, Katayama Y, Kimura A, Kobayashi S: VII. Rehabilitation. J Stroke Cerebrovasc Dis 2011;20(suppl 1):S145-S180.

$>8$ European Stroke Organisation (ESO) Executive Committee, ESO Writing Committee: Guidelines for management of ischaemic stroke and transient ischaemic attack 2008. Cerebrovasc Dis 2008;25:457-507.

9 ESO News: Update Guidelines January 2009. Specific Treatment: Thrombolysis. Cerebrovasc $\mathrm{Dis} 2009 ; 27: 619-620$.

10 Neuroresuscitation; in JRC Guidelines 2010 (in Japanese). Tokyo, Japan Resuscitation Council, 2010. http://jrc.umin.ac.jp/pdf/20121022_NR_ E.pdf.

11 Wojner-Alexander AW, Garami Z, Chernyshev OY, Alexandrov AV: Heads down: flat positioning improves blood flow velocity in acute ischemic stroke. Neurology 2005;64: 1354-1357.

-12 Sandset EC, Bath PM, Boysen G, Jatuzis D, Kõrv J, Lüders S, Murray GD, Richter PS, Roine RO, Terént A, Thijs V, Berge E, SCAST Study Group: The angiotensin-receptor blocker candesartan for treatment of acute stroke (SCAST): a randomised, placebo-controlled, doubleblind trial. Lancet 2011;377:741-750.

13 Minematsu K, Toyoda K, Hirano T, Kimura K, Kondo R, Mori E, Nakagawara J, Sakai N, Shiokawa Y, Tanahashi N, Yasaka M, Katayama Y, Miyamoto S, Ogawa A, Sasaki M, Suga S, Yamaguchi T: Guidelines for intravenous application of rt-PA (alteplase), the second edition, October 2012: a guideline from the Japan Stroke Society. J Stroke Cerebrovasc Dis 2013, in press.

$\checkmark 14$ Yamaguchi T, Mori E, Minematsu K, Nakagawara J, Hashi K, Saito I, Shinohara Y, Japan Alteplase Clinical Trial (J-ACT) Group: Alteplase at $0.6 \mathrm{mg} / \mathrm{kg}$ for acute ischemic stroke within 3 hours of onset: Japan Alteplase Clinical Trial (J-ACT). Stroke 2006; 37:1810-1815.

-15 Mori E, Minematsu K, Nakagawara J, Yamaguchi T, Sasaki M, Hirano T, Japan Alteplase Clinical Trial II Group: Effects of $0.6 \mathrm{mg} / \mathrm{kg}$ intravenous alteplase on vascular and clinical outcomes in middle cerebral artery occlusion: Japan Alteplase Clinical Trial II (J-ACT II). Stroke 2010;41:461-465.

- 16 Jauch EC, Saver JL, Adams HP Jr, Bruno A, Connors JJ, Demaerschalk BM, Khatri P, McMullan PW Jr, Qureshi AI, Rosenfield K, Scott PA, Summers DR, Wang DZ, Wintermark M, Yonas H, American Heart Association Stroke Council, Council on Cardiovascular Nursing, Council on Peripheral Vascular Disease, Council on Clinical Cardiology: Guidelines for the early management of patients with acute ischemic stroke: a guideline for healthcare professionals from the American Heart Association/American Stroke Association. Stroke 2013;44:870-947.

17 Ogawa A, Mori E, Minematsu K, Taki W, Takahashi A, Nemoto S, Miyamoto S, Sasaki
M, Inoue T, MELT Japan Study Group: Randomized trial of intraarterial infusion of urokinase within 6 hours of middle cerebral artery stroke: the middle cerebral artery embolism local fibrinolytic intervention trial (MELT) Japan. Stroke 2007;38:2633-2639.

18 Tazaki Y, Kobayashi S, Tohgi H, et al: Clinical benefit of an antithrombin agent, MD-805, in acute-phase cerebral thrombosis - a placebocontrolled, multicenter, double-blind, intergroup trial (in Japanese)]. J Clin Exp Med 1992;161:887-907.

19 Kobayashi S, Tazaki Y: Effect of the thrombin inhibitor argatroban in acute cerebral thrombosis. Semin Thromb Hemost 1997;23:531534.

20 Fukuuchi Y, Tohgi H, Shinohara Y, et al: A controlled clinical trial to assess the efficacy and safety of argatroban in treating acute cerebral thrombosis in comparison to sodium ozagrel (in Japanese). Neurol Ther 2001;18: 273-282.

21 Otomo E, Kutuzawa T, Kogure K: Clinical benefit of OKY-046 in acute cerebral thrombosis - a placebo-controlled, multicenter, double-blind trial (in Japanese). J Clin Ther Med 1991;7:353-388.

-22 Edaravone Acute Infarction Group: Effect of a novel free radical scavenger, edaravone (MCI-186), on acute brain infarction. Randomized, placebo-controlled, double blind study at multicenters. Cerebrovasc Dis 2003; 15:222-229.

23 Ringelstein EB, Chamorro A, Kaste M, Langhorne P, Leys D, Lyrer P, Thijs V, Thomassen L, Toni D, ESO Stroke Unit Certification Committee: European Stroke Organisation recommendations to establish a stroke unit and stroke center. Stroke 2013; 44:828-840.

24 Ogihara T, Kikuchi K, Matsuoka H, Fujita T, Higaki J, Horiuchi M, Imai Y, Imaizumi T, Ito S, Iwao H, Kario K, Kawano Y, Kim-Mitsuyama S, Kimura G, Matsubara H, Matsuura H, Naruse M, Saito I, Shimada K, Shimamoto K, Suzuki H, Takishita S, Tanahashi N, Tsuchihashi T, Uchiyama M, Ueda S, Ueshima $\mathrm{H}$, Umemura S, Ishimitsu T, Rakugi $\mathrm{H}$, Japanese Society of Hypertension Committee: The Japanese Society of Hypertension Guidelines for the Management of Hypertension (JSH 2009). Hypertens Res 2009;32:3-107, erratum $\mathrm{p} 318$.

25 Mancia G, De Backer G, Dominiczak A, Cifkova R, Fagard R, Germano G, Grassi G, Heagerty AM, Kjeldsen SE, Laurent S, Narkiewicz K, Ruilope L, Rynkiewicz A, Schmieder RE, Struijker Boudier HA, Zanchetti A, Vahanian A, Camm J, De Caterina R, Dean V, Dickstein K, Filippatos G, Funck-Brentano C, Hellemans I, Kristensen SD, McGregor K, Sechtem U, Silber S, Tendera M, Widimsky P, Zamorano JL, Kjeldsen SE, Erdine S, Narkiewicz K, Kiowski W, Agabiti-Rosei E, Ambrosioni E, Cifkova R, Dominiczak A, Fagard R, Heagerty AM, Laurent S, Lindholm LH, Mancia G, Manolis A, Nilsson PM, Redon J, Schmieder RE, Struijker-Boudier HA, Viigi- maa M, Filippatos G, Adamopoulos S, Agabiti-Rosei E, Ambrosioni E, Bertomeu V, Clement D, Erdine S, Farsang C, Gaita D, Kiowski W, Lip G, Mallion JM, Manolis AJ, Nilsson PM, O'Brien E, Ponikowski P, Redon J, Ruschitzka F, Tamargo J, van Zwieten P, Viigimaa M, Waeber B, Williams B, Zamorano JL, Task Force for the Management of Arterial Hypertension of the European Society of Hypertension, Task Force for the Management of Arterial Hypertension of the European Society of Cardiology: 2007 Guidelines for the management of arterial hypertension: the Task Force for the Management of Arterial Hypertension of the European Society of Hypertension (ESH) and of the European Society of Cardiology (ESC). Eur Heart J 2007;28: 1462-536.

26 Cholesterol Treatment Trialists' (CTT) Collaborators, Kearney PM, Blackwell L, Collins R, Keech A, Simes J, Peto R, Armitage J, Baigent C: Efficacy of cholesterol-lowering therapy in 18,686 people with diabetes in 14 randomised trials of statins: a meta-analysis. Lancet 2008;371:117-125.

27 Sato H, Ishikawa K, Kitabatake A, et al: Lowdose aspirin for prevention of stroke in lowrisk patients with atrial fibrillation: Japan Atrial Fibrillation Stroke Trial. Stroke 2006; 37:447-451.

28 Yamaguchi T, Japanese Nonvalvular Atrial Fibrillation-Embolism Secondary Prevention Cooperative Study Group: Optimal intensity of warfarin therapy for secondary prevention of stroke in patients with nonvalvular atrial fibrillation: a multicenter, prospective, randomized trial. Stroke 2000;31:817-821.

29 Yasaka M, Minematsu K, Yamaguchi T: Optimal intensity of international normalized ratio in warfarin therapy for secondary prevention of stroke in patients with non-valvular atrial fibrillation. Intern Med 2001;40: 1183-1188.

30 Stroke Prevention in Atrial Fibrillation Investigators: Adjusted-dose warfarin versus lowintensity, fixed-dose warfarin plus aspirin for high-risk patients with atrial fibrillation: Stroke Prevention in Atrial Fibrillation III randomised clinical trial. Lancet 1996;348:633638.

31 Hylek EM, Singer DE: Risk factors for intracranial hemorrhage in outpatients taking warfarin. Ann Intern Med 1994;120:897-902.

32 Hobson R 2nd, Krupski W, Weiss D: Influence of aspirin in the management of asymptomatic carotid artery stenosis. VA Cooperative Study Group on Asymptomatic Carotid Stenosis. J Vasc Surg 1993;17:257-263.

33 Engelter S, Lyrer P: Antiplatelet therapy for preventing stroke and other vascular events after carotid endarterectomy (review). Cochrane Database Syst Rev 2003;3:CD001458.

- 34 Mayo Asymptomatic Carotid Endarterectomy Study Group: Results of a randomized controlled trial of carotid endarterectomy for asymptomatic carotid stenosis. Mayo Asymptomatic Carotid Endarterectomy Study Group. Mayo Clin Proc 1992;67:513-518. 
-35 Tanaka K, Ishikawa Y, Yokoyama M, Origasa $\mathrm{H}$, Matsuzaki M, Saito Y, et al: Reduction in the recurrence of stroke by eicosapentaenoic acid for hypercholesterolemic patients: subanalysis of the JELIS trial. Stroke 2008;39: 2052-2058.

>36 Reynolds K, Lewis B, Nolen JD, Kinney GL, Sathya B, He J: Alcohol consumption and risk of stroke: a meta-analysis. JAMA 2003;289: 579-588.

-37 Diener HC, Cunha L, Forbes C, Sivenius J, Smets P, Lowenthal A: European Stroke Prevention Study. 2. Dipyridamole and acetylsalicylic acid in the secondary prevention of stroke. J Neurol Sci 1996;143:1-13.

38 Halkes P, van Gijn J, Kappelle L, Koudstaal P, Algra A: Aspirin plus dipyridamole versus aspirin alone after cerebral ischaemia of arterial origin (ESPRIT): randomised controlled trial. Lancet 2006;367:1665-1673.
39 CAPRIE Steering Committee: A randomised, blinded trial of clopidogrel versus aspirin in patients at risk of ischaemic events (CAPRIE). Lancet 1996;348:1329-1339.

40 Costa J, Ferro JM, Matias-Guiu J, AlvarezSabin J, Torres F: Triflusal for preventing serious vascular events in people at high risk. Cochrane Database Syst Rev 2005; 3:CD004296.

41 Diener H, Bogousslavsky J, Brass L, Cimminiello C, Csiba L, Kaste M, Leys D, MatiasGuiu J, Rupprecht H: Aspirin and clopidogrel compared with clopidogrel alone after recent ischaemic stroke or transient ischaemic attack in high-risk patients (MATCH): randomised, double-blind, placebo-controlled trial. Lancet 2004;364:331-337.

42 Gotoh F, Tohgi H, Hirai S, Terashi A, Fukuuchi Y, Otomo E, et al: Cilostazol stroke prevention study: a placebo-controlled doubleblind trial for secondary prevention of cerebral infarction. J Stroke Cerebrovasc Dis 2000;9:147-157.
43 Huang Y, Cheng Y, Wu J, Li Y, Xu E, Hong Z, et al: Cilostazol as an alternative to aspirin after ischaemic stroke: a randomised, double-blind, pilot study. Lancet Neurol 2008;7:494-499.

44 Shinohara Y, Katayama Y, Uchiyama S, Yamaguchi T, Handa S, Matsuoka K, Ohashi Y, Tanahashi N, Yamamoto H, Genka C, Kitagawa Y, Kusuoka H, Nishimaru K, Tsushima M, Koretsune Y, Sawada T, Hamada C, CSPS 2 Group: Cilostazol for prevention of secondary stroke (CSPS 2): an aspirin-controlled, double-blind, randomised noninferiority trial. Lancet Neurol 2010;9:959-968.

45 Japanese Circulation Society. Circ J 2004; 68(suppl IV):1195-1196.

46 Powers WJ, Clarke WR, Grubb RL Jr, Videen TO, Adams HP Jr, Derdeyn CP, COSS Investigators: Extracranial-intracranial bypass surgery for stroke prevention in hemodynamic cerebral ischemia: the Carotid Occlusion Surgery Study randomized trial. JAMA 2011;306: 1983-1992. 